- News \& Views •

\title{
The 13th and 14th Workshops on Antarctic Meteorology and Climate
}

\author{
Matthew A. LAZZARA*1,2, Sophie A. ORENDORF ${ }^{1,3}$, Taylor P. NORTON ${ }^{1,3}$, Jordan G. POWERS ${ }^{4}$, \\ David H. BROMWICH ${ }^{5}$, Scott CARPENTIER ${ }^{6}$, John J. CASSANO ${ }^{7}$, Steven R. COLWELL ${ }^{8}$, \\ Arthur M. CAYETTE 9 , and Kirstin WERNER ${ }^{10}$ \\ ${ }^{1}$ Antarctic Meteorological Research Center, Space Science and Engineering Center, \\ University of Wisconsin-Madison, Madison, WI 53706, USA \\ ${ }^{2}$ Department of Physical Sciences, School of Arts and Sciences, Madison Area Technical College, Madison WI 53704, USA \\ ${ }^{3}$ Department of Atmospheric Sciences, University of Wisconsin-Madison, Madison, WI 53706, USA \\ ${ }^{4}$ National Center for Atmospheric Research, Boulder CO 53706, USA \\ ${ }^{5}$ Polar Meteorology Group, Byrd Polar \& Climate Research Center, The Ohio State University, Columbus OH 43210, USA \\ ${ }^{6}$ Bureau of Meteorology, Hobart, Tasmania 7001, Australia \\ ${ }^{7}$ Cooperative Institute for Research in Environmental Sciences and Department of Atmospheric and Oceanic Sciences, \\ University of Colorado, Boulder, CO 80309, USA \\ ${ }^{8}$ British Antarctic Survey, Cambridge CB3 0ET, United Kingdom \\ ${ }^{9}$ Naval Information Warfare Center, Charleston, SC 29406, USA \\ ${ }^{10}$ Year of Polar Prediction (YOPP) International Coordination Office, Alfred Wegener Institute, \\ Helmholtz, Centre for Polar and Marine Research, Bremerhaven 27570, Germany
}

(Received 10 October 2019; revised 19 November 2019; accepted 27 November 2019)

Citation: Lazzara, M. A., and Coauthors, 2020: The 13th and 14th Workshops on Antarctic Meteorology and Climate. Adv. Atmos. Sci., 37(5), 423-430, https://doi.org/10.1007/s00376-019-9215-6.

\section{Overview}

In July 2018, the Antarctic community came together to meet at the 13th Workshop on Antarctic Meteorology and Climate (WAMC) in Madison, Wisconsin, USA (Fig. 1); and in the following year in June 2019, the 14th WAMC was held in Charleston, South Carolina, USA (Fig. 2). With a growing history, the WAMC addresses the topics of Antarctic meteorology and climate (Kameda et al., 2008; Colwell et al., 2016; Lazzara et al., 2018) as well as weather-related issues of scientific and operational support. The workshops bring together researchers, operational forecasters, numerical modelers, observational specialists, and students. The themes of both workshops included Antarctic meteorological observations, Antarctic atmospheric numerical modeling, Antarctic meteorological and climate research, and Antarctic weather forecasting and operational services. The 2018 and 2019 WAMC were both followed by a one-day focus on the Year of Polar Prediction-Southern Hemisphere (YOPP-SH), when preparations and follow-up discussions were made with regard to the YOPP Special Observing Period from 16 November 2018 to 15 February 2019.

\section{Theme 1: Antarctic meteorological observations}

The 2018 and 2019 WAMC had sessions covering Antarctic environmental observations. The first encompassed active weather observing stations, observing equipment, and operational applications. The second focused on future observing and data collection systems. Nine presentations from six different agencies were presented during this portion of the program. The reports described current observational support across Antarctica, listing types of systems, modifications, locations, problems, concerns, and accessibility. The presentations explained current and planned observing systems, datasets currently available, data collection efforts underway, and vulnerabilities in support of regional monitoring systems. This component of the

\footnotetext{
* Corresponding author: Matthew A. LAZZARA

Email: mlazzara@madisoncollege.edu
} 


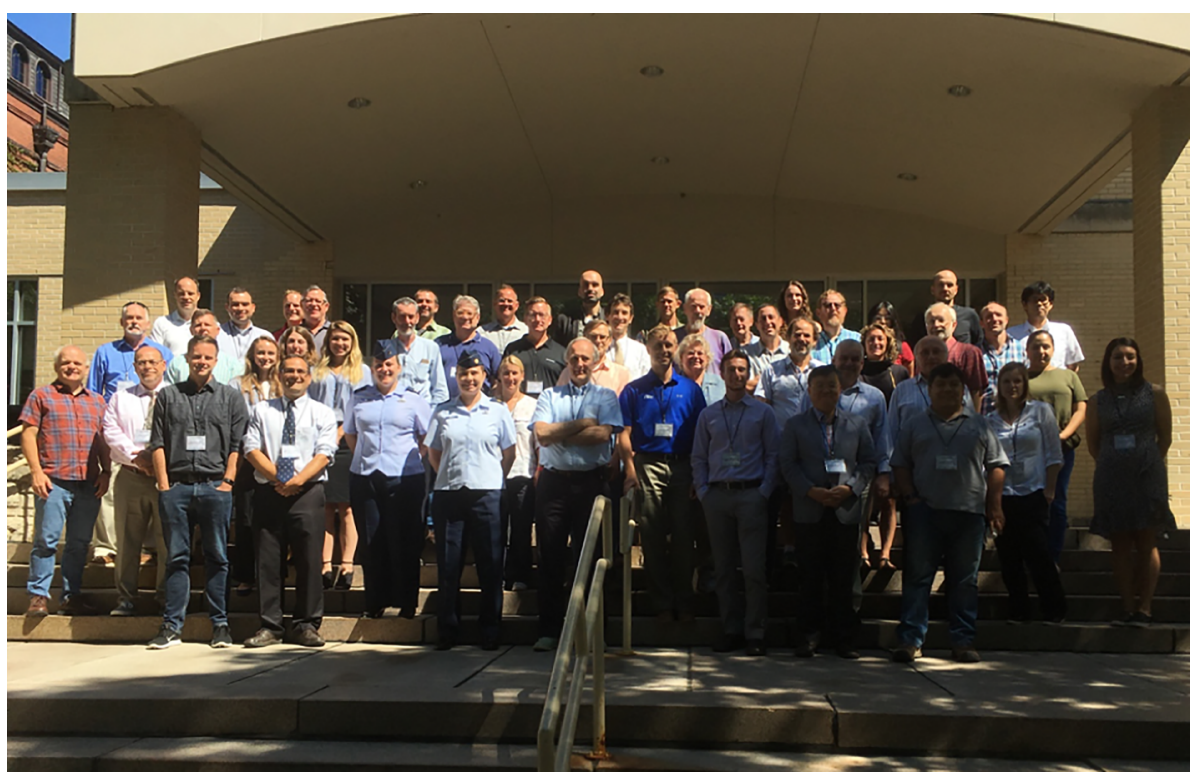

Fig. 1. The 58 attendees at the 13th WAMC (2018) represented over 10 countries and included participation from every continent.

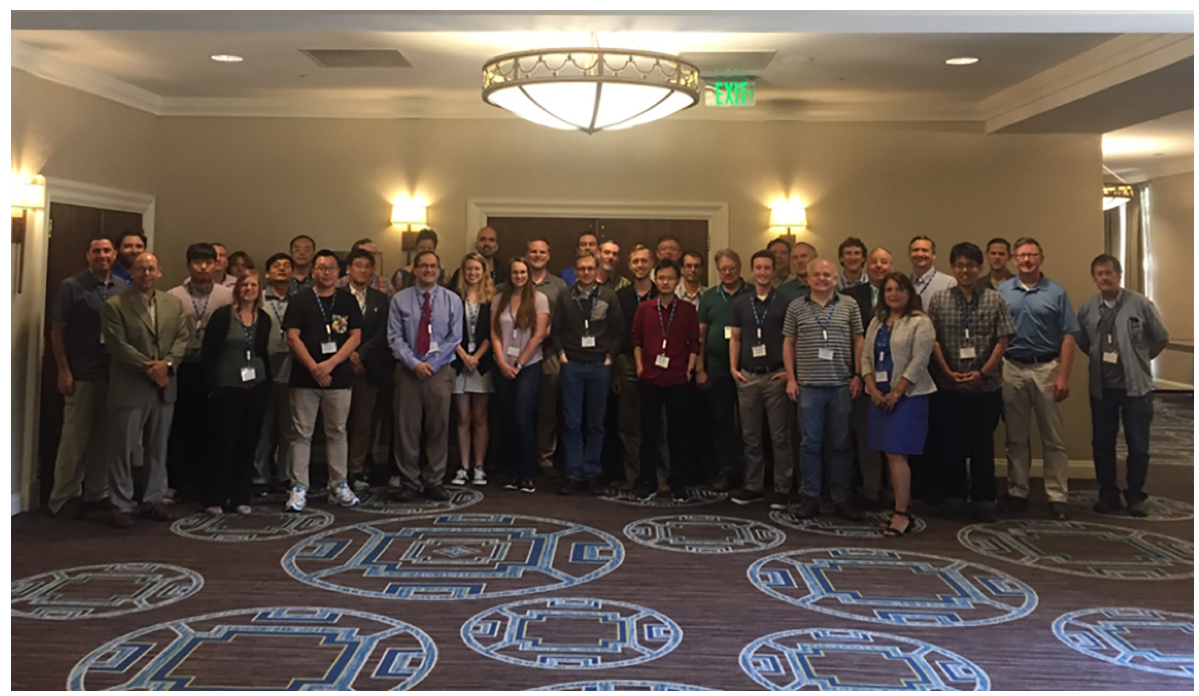

Fig. 2. The 55 attendees at the 14 th WAMC (2019) represented 10 countries.

workshop informs the community of both data availability and needs in the observation systems across Antarctica.

\subsection{Status}

The Antarctic atmosphere is observed through various capabilities: at the surface via automatic and staffed weather stations, through the troposphere via radiosondes and aircraft, and from above via satellites. Both the 2018 and 2019 workshops reviewed the status of the surface observing networks across the continent (Fig. 3 and Fig. 4). Specifically, the British Antarctic Survey (BAS) and the Antarctic Meteorological Research Center provided updates on their respective networks. Representatives of individual staffed stations reviewed their sites' observing programs, including those at King Sejong and Jang Bogo stations. Specific observing programs, such as the Antarctic Precipitation Systems project, were discussed, and plans for the testing of a portable Doppler X-band radar system at Phoenix Airfield at McMurdo Station during the 2019-20 field season were presented.

In 2018, BAS discussed their participation in a Vaisala radiosonde trial, which compared new RS41 radiosondes to the older RS92 technology. The workshops make it apparent that AWS networks will be evolving. For example, the Chinese Antarctic Research Expedition aims to expand its network with several new AWS systems planned for installation between Kunlun Station (at Dome Argus in East Antarctica) and Zhongshan Station near Prydz Bay. Additional plans are in place for the Madison College Polar Climate and Weather Station project to install up to five test systems at existing AWS locations for trials in the 2019-20 field season. 


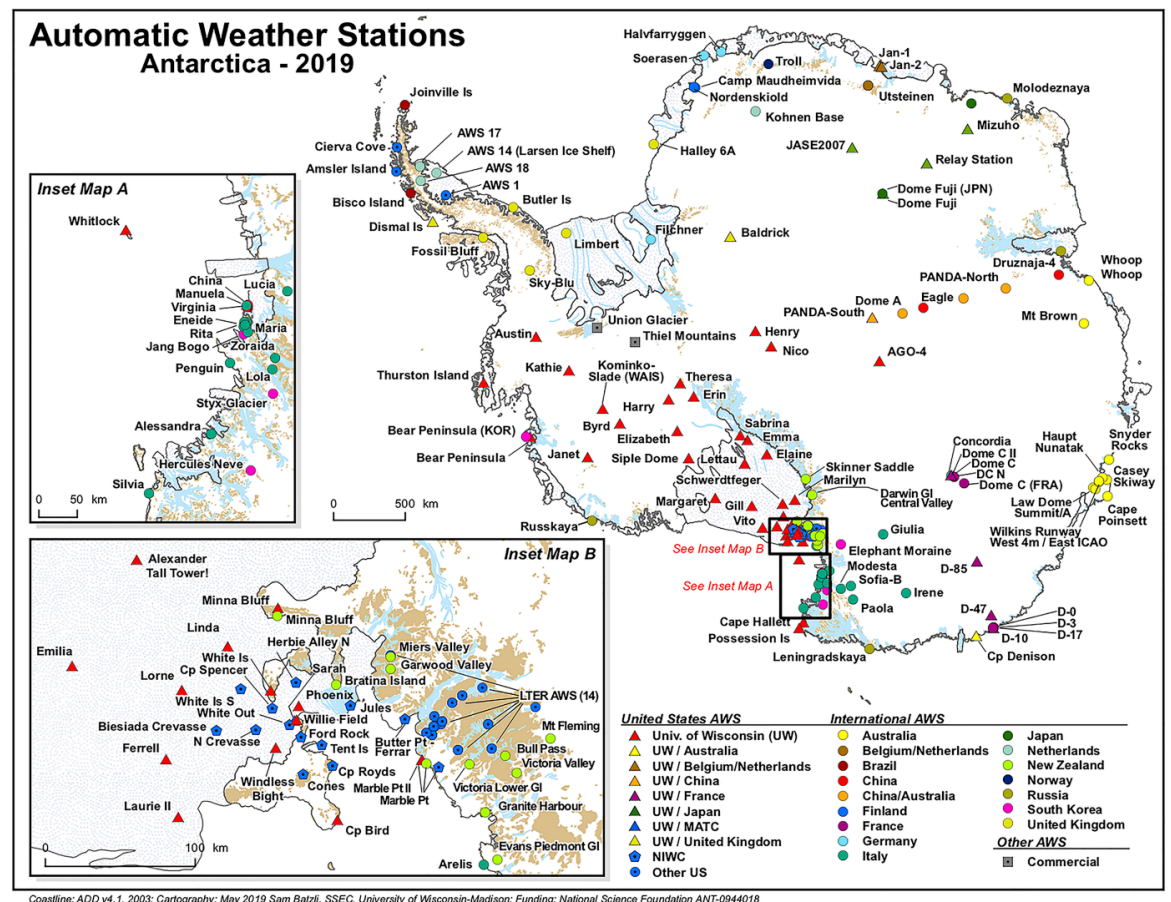

Fig. 3. A map of the AWS network on Antarctica as of 2019.

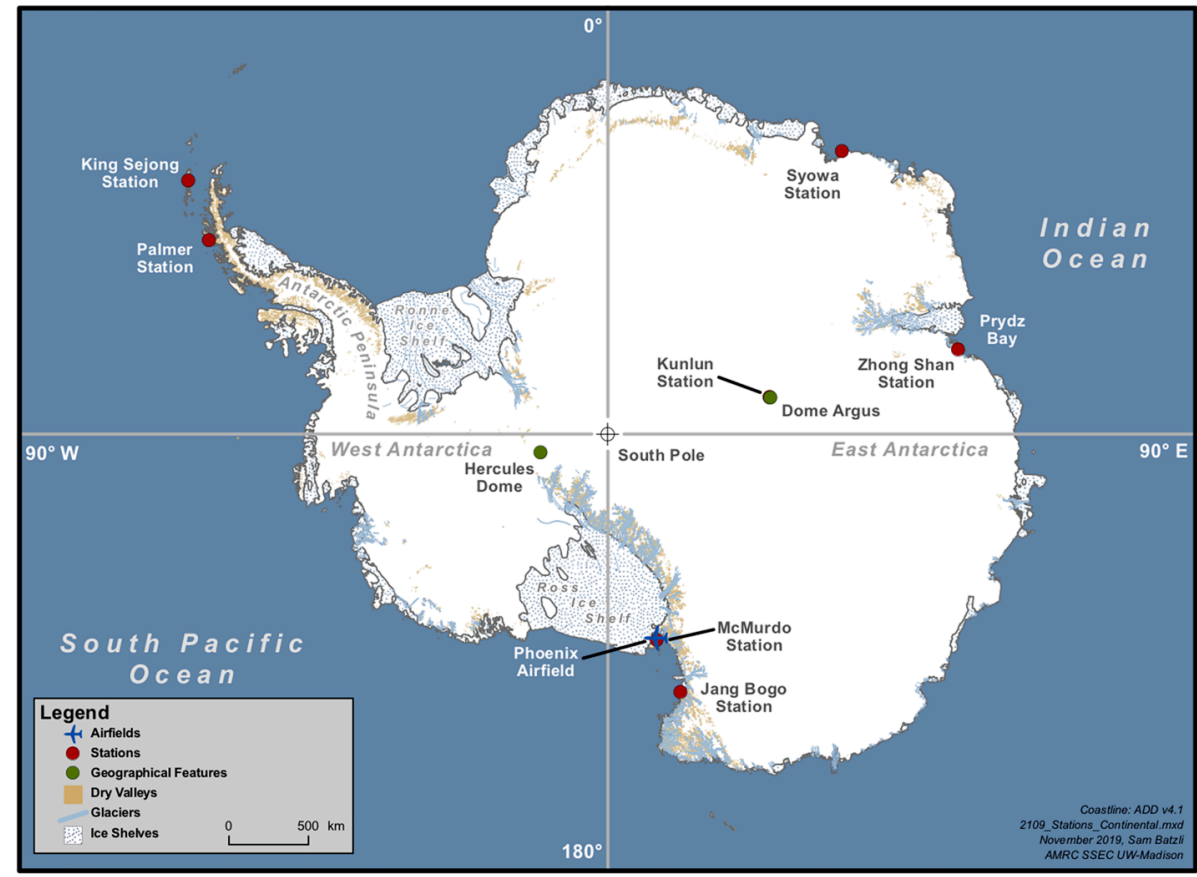

Fig. 4. A map of key geographic locations in and around Antarctica.

\subsection{Challenges}

The workshop provides an opportunity for participants to voice concerns and identify challenges and needs. The intention of the group interactions was to gain greater understanding of individual project requirements, as well as potential uses, applications, and modifications that could improve Antarctic observing efforts.

One area of concern is having more robust datasets from the surface and upper air in light of three-hourly synoptic outputs from existing staffed stations and AWS sites. A particular issue is whether there could be a better distribution model for the datasets. Several issues were raised about the AWS sites, including concerns about the infrequent visits to certain sites. Not visiting for multiple years can impact the accuracy and availability of data. The ability to expand the AWS sensor 
set to include a camera for both science applications and system monitoring was noted as desirable. There was an emphasis on the importance of having improved metadata, along with the need for a consistent, standard quality control process applied to all observational datasets.

Discussions on the meteorological data generated by Antarctic observing systems indicated the value of the Observing Systems Capability Analysis and Review Tool provided by the World Meteorological Organization (WMO) to manage metadata. Operators of networks, such as the various Antarctic AWS networks, require editing privileges. This allows for better management of new stations and new capabilities, such as the addition of radiosondes sites. The implementation of the new WMO Integrated Global Observing System (WIGOS) Identification (ID) system may be delayed due to issues linking to historical datasets and numerical weather prediction (NWP) centers being ready to accept the new WIGOS ID numbering schemes.

Topics concerning data distribution included having aircraft observations made available for later use in numerical model assimilation. It was recognized that putting the observations into the WMO's Global Telecommunications System (GTS) is essential. Another means for distributing and sharing observations is via the Antarctic Internet Data Distribution system (Antarctic-IDD) (Seefeldt et al., 2009). A request was made for more Antarctic-IDD participation from the international community. The Antarctic-IDD network is in need of more stability with increased nodes for data relay and distribution, as well as having additional participants contributing new datasets (e.g., numerical model output, observations, etc.). Other discussions covered the observational dataset formats, quality control and the potential installation of additional tall tower AWS systems.

\section{Theme 2: Antarctic atmospheric numerical modeling}

Numerical modeling over Antarctica and the high southern latitudes is a perennial focus at the WAMC. For both workshops, modeling-related presentations addressed both real-time forecasting and research applications. The 2019 WAMC included talks on the state of the Antarctic Mesoscale Prediction System (AMPS), developments in the polar-modified version of the Weather Research and Forecasting (WRF) model (Skamarock et al., 2019) (Polar WRF), and Polar WRF's simulation of Antarctic clouds. The community was updated on a study using the AMPS framework to investigate the forecast impact of YOPP-SH Special Observing Period (SOP) soundings. The workshop also addressed climate modeling, and a regional climate simulation covering the Antarctic Peninsula for 1991-2015. This work involved Polar WRF driven by ERA-Interim data. The results showed an annual cooling trend for the leeward side of the Peninsula and a warming trend for the windward side, in agreement with observations.

\subsection{Challenges}

The WAMC modeling discussions encompassed model evaluation and development, atmospheric process research and case studies, and forecasting for Antarctic programs. Two challenges recognized at the workshop were the identification of modeling system weaknesses and the improvement of codes for the polar application. For example, model deficiencies in high-latitude cloud and planetary boundary layer (PBL) representation have been recurring workshop topics and are viewed as prime targets for improvement. At the 2019 WAMC, a presentation of Antarctic WRF forecast results highlighted needs to address: (1) model clouds and microphysics; (2) surface temperature warm biases; and (3) the representation of diurnal temperature cycles. Another presentation illustrated the use of special measurements from the 2015-16 ARM (Atmospheric Radiation Measurement Program) West Antarctic Radiation Experiment to reveal a liquid water deficit in clouds in AMPS WRF forecasts, leading to the cloud radiative effect being too small (Hines et al., 2019).

Such workshop results point to the need to run sufficiently sophisticated microphysics schemes in models over Antarctica. The challenge here is not only for AMPS, but also for all groups running NWP models over Antarctica, is to use microphysics schemes that can simulate the observed liquid water presence and capture the increased cloud radiative effects, while being affordable computationally (e.g. Hong et al., 2004). As microphysics choice in WRF is constrained by AMPS computer limitations, with alternative schemes being significantly more expensive to run, the issues for real-time modelers are not just in identifying a better microphysics package, but in having the resources to run it.

The Naval Information Warfare Center (NIWC) delivers the weather forecasting to the U.S. Antarctic Program (USAP), and it annually evaluates its forecast performance. It reported that its recent forecast quality/success levels have generated net savings for the USAP, a critical accomplishment benefitting the program. This performance level is a reflection of forecaster experience, NIWC's refined training program, and the vital guidance of AMPS. Here, ongoing challenges for NIWC and its forecaster subcontractor, DIGITALiBiz, are to maintain the high forecast quality and for AMPS to continue to improve its numerical guidance and products.

A specific test for USAP operational support is temperature forecasting for the South Pole. South Pole aircraft transport faces operating limitations at temperatures below $-40^{\circ} \mathrm{C}$. Forecast accuracy when conditions are that cold is critical. This is another challenge raised at the WAMC_-improving Antarctic temperature forecasts in regimes of borderline aircraft operating conditions. 
The United States Air Force (USAF) was also represented at the 14th WAMC and presented its interests in high-latitude NWP for its dual-pole operations - in particular, its mission of providing heavy-lift transport for the USAP. One issue noted was to improve the USAF's operational model to incorporate polar optimizations. In this area, coordination-facilitated by the WAMC - with efforts like AMPS and polar modelers from the research and operational communities, would be a step toward advancing the USAF's capabilities.

\subsection{Outcomes}

The WAMC makes clear that community work to polar-optimize the physics schemes of models will continue. The process is iterative, with model evaluation followed by code modification. Furthermore, while polar physics development tends to be model-specific, there are efforts to create software frameworks/interfaces to allow such code developments to be shared widely and thus to improve a range of models. These frameworks aim to support the use of different physics packages across NWP models, and a prime example is the Community Common Physics Package led by NOAA (https://dtcenter.org/community-code/common-community-physics-package-ccpp). This type of broader development effort will facilitate the polar research community's efforts to meet the challenge of improving numerical models for high-latitude applications. Understanding the impacts of enhanced high-latitude observations on Antarctic NWP will be pursued both through the AMPS YOPP-SH study and similar investigations by the international polar community. Future WAMCs, other meteorological conferences, and publications will present the findings garnered from the YOPP-SH SOP campaign. One expected outcome is advancing the goal of the YOPP-SH's parent program, the WMO Polar Prediction Project (PPP), to improve numerical prediction. A subsequent outcome may be a strong argument by the Antarctic community for national programs to continue enhanced Southern Hemisphere observation efforts, as per the YOPP-SH example.

\section{Theme 3: Antarctic meteorological and climate research}

Discussion of recent research in Antarctic meteorology and climate is another core element of each WAMC. Covering a wider range of topics than other workshop sections, this theme provides an overview of current research activities spanning short-term weather events to long-term climate studies exploiting in-situ observations, satellite remote sensing, reanalysis data, and model output.

\subsection{Challenges}

A challenge for all polar atmospheric research is the sparse in-situ observational network and the irregular and/or short time period of these observational data, with only a limited number of sites having data spanning multiple decades. In addition, many of the in-situ observations are surface-based, making it difficult to assess three-dimensional atmospheric features. The Antarctic research community overcomes these issues through extensive use of the widespread surface AWS network and staffed station observations supplemented with satellite, reanalysis, and model data, as well as the use of newer observing systems, such as autonomous aircraft.

\subsection{Outcomes}

In the 2018 WAMC, six of the seven presentations in this theme discussed anomalous warm or snow melting events. One study illustrated the use of AWS data to analyze rapid wintertime warming events, while two examined the impact of foehn events on West Antarctic melt and a record warm event near the Antarctic Peninsula using AWS data and model simulations. The other presentations reported on warming trends over the mid and high southern latitudes for the past 60 years and wind impacts on surface temperature anomalies. Reflecting the bi-polar interests of the workshop participants, a study on warming over the Greenland ice sheet based on current and future climate model simulations was also presented.

The 2019 WAMC presentations focused more on regional meteorology. For example, one report analyzed the meteorology of Hercules Dome in the context of that area being a future deep ice-core site. Both the Korean and Japanese Antarctic programs presented observational studies from King Sejong Station and from the Syowa traverse route, emphasizing the value of observer-based data for Antarctic research. Two presentations focused on operational meteorology aspects of the USAP: a review of weather events impacting McMurdo Station during the 2018-2019 operating season, and a study of the weather at Marble Point, important for aviation support. Also shared with the community was a review of small, unmanned research aircraft used to study the Antarctic boundary layer.

\section{Theme 4: Antarctic weather forecasting and operational services}

The weather forecasting and operational services discussions at the 2018 and 2019 WAMCs considered a number of potential approaches to improving forecasting in Antarctica. As observations are central to operational forecasts, there were overlapping discussions of national data availability, reliability, and observation expansion to support weather monitoring and numerical modeling. 


\subsection{Challenges}

The basic challenge of weather forecasting for Antarctica is characterized by the scarcity of data and the complexity of the meteorology. The WAMC assists in this effort as a forum dedicated to collectively furthering the understanding of weather, climate, and the operational challenges of Antarctica with active discussion between operational forecasters, modelers, and researchers.

Services provided for operational or research purposes require the information to be meaningful, timely, and accurate. Through the workshops' collaboration of dedicated professionals, the presentation of shared ideas and accomplishments allows the participants to learn of both shortfalls and successes and to work to provide better services to their customers.

\subsection{Outcomes}

For the 2018-19 USAP operational season, evaluation of numerical prediction temperature values was conducted by NIWC. A low bias for temperature forecasts for South Pole Station from both WRF (from AMPS) and the Global Forecasting System was found. The NIWC group also evaluated the model forecasts of maximum and minimum temperature and also found that there was a low temperature bias at McMurdo Station and Palmer Stations. These results, however, revealed an improvement over a previous temperature forecast evaluation by Asuma and Lazzara (2008). Continued work in this area will include improving NWP initial conditions through more surface observations and improved data quality control. Funding has been granted for an additional Tall Tower, to be installed in West Antarctica, and added sensors to assist in understanding the surface and PBL interactions.

To improve forecasts and data availability, NIWC discussed additions to the AWS network, providing new observing kits offering round-the-clock automated observations, and improving training techniques. The kits are portable AWSs that measure the basic meteorological parameters (e.g., temperature, wind, etc.). New portable weather kits were presented as a plan in the 2018 workshop and fielded in 2018. Results and a live display were presented during the 2019 workshop. The Australian Bureau of Meteorology's presentation on the Southern Ocean Clouds Radiation Aerosol Transport experimental study showed that they had improved their confidence in airframe icing warnings with collected cloud, aerosol, and precipitation data over the Southern Ocean. A greatly increased number of Southern Hemisphere observations was realized for the YOPP-SH effort. This meaningful data supplement should aid significantly in meteorological analyses and may prove to be of benefit for improving Antarctic numerical forecasting.

\section{Theme 5: YOPP-SH}

The advancement of NWP models, including physical linkages to lower latitudes, and their verification, is particularly relevant to enhance forecasting services for the Antarctic and beyond. The YOPP is the flagship activity of the decade-long PPP that has been initiated by the WMO's World Weather Research Programme to improve predictive skill in both polar regions (Carrasco and Uribe, 2019). Being considered as the core phase of the PPP, the YOPP took place from mid-2017 to mid-2019. During three month-long SOPs, routine meteorological and sea-ice measurements in the Arctic and Antarctic were complemented by additional observations to allow for enhanced NWP experiments in order to refine locations and frequency of data required to improve weather and sea-ice forecasts. The SOP in the Southern Hemisphere (SOP-SH1) took place during the austral field summer season from 16 November 2018 to 15 February 2019. Almost 2100 extra radiosondes were released from meteorological stations and vessels. The extra observations resulted in a pronounced improvement of NWP skill.

YOPP-SH meetings have been organized annually since 2016, aligned with the WAMC meeting. The purpose of the 2018 meeting was to finalize the different nations' contributions to the SOP, while the 2019 meeting aimed at summarizing the extra observations and modeling efforts during SOP-SH1. Additionally, the meeting was used to define next steps in view of consolidating research activities and translation into improved weather and sea-ice services for the Antarctic and the Southern Ocean.

The third YOPP-SH meeting was held in conjunction with the 13th WAMC. Scientists and representatives of operational weather services, with research and operational/logistical interests in Antarctic meteorology and forecasting, discussed related activities. In particular, project investigators and representatives of national agencies operating in Antarctica provided updates on the current status of planning with regard to SOP-SH1. Amongst others, operational NWP support provided by the involved national weather centers was discussed. The Antarctic YOPP supersites were highlighted as key locations for process-based verification of model-based forecasts against high-frequency observations. In addition to plans for SOP-SH1, the oceanographic community, in particular, suggested another ("light version") SOP during austral winter.

The fourth YOPP-SH meeting took place following the 14th WAMC. The meeting aimed at bringing together all parties involved in Antarctic meteorology and the advancement of this discipline through scientific research and improving operational support during the YOPP. The high-resolution radiosonde data from the SOP-SH1 campaign was collected by the BAS and is available at ftp://ftp.bas.ac.uk/src/YOPP-SH/radiosondes. An overview on the radiosoundings on the GTS during SOP-SH1 was made available by the National Center for Atmospheric Research at http://www2.mmm.ucar.edu/ 
rt/amps/information/YOPP_SH_SOP_raob_accounting.html.

\subsection{Challenge: Sea-ice prediction in Antarctica}

One of the flagship activities of YOPP-SH is the Sea Ice Prediction Network South (SIPN South), initiated in 2017. SIPN South was launched due to the increasing need for sea-ice information in the Southern Ocean, the existence of predictability mechanisms for summer sea ice recently suggested in the scientific literature, and the lack of knowledge regarding the skill of state-of-the-art operational forecasts at the seasonal time scale.

Almost 200 forecasts were submitted in late November 2018 to the SIPN South initiative to predict the sea-ice conditions of the following austral summer. Meanwhile, in the test season of summer 2017-18, the unusual ice retreat in the Ross Sea was successfully predicted by a dynamical model; and during summer 2018-19, it was statistical forecast models that had a lower prediction error. Forecast data and scripts to create the figures presented in reports, posters, and presentations are publicly available from an online repository (https://github.com/fmassonn/sipn-south-public).

During the 2019 meeting, it was agreed to hold a second Southern Hemisphere Special Observing Period (SOP-SH2) during the Antarctic winter. In order to cover the sea-ice growth in early winter, the intent is to schedule it between mid-April to mid-July 2021.

\subsection{Challenge: Impact of YOPP on society}

Engagement with users of Antarctic forecasting services is a key component of PPP. In order to estimate the societal impact of the YOPP, the Societal and Economic Research and Applications group (PPP-SERA) is active in stakeholder engagement and collecting requirements of Antarctic operators who use weather and sea-ice forecasts for their decision-making. PPP-SERA was involved in the discussions at the YOPP-SH meetings in 2018 and 2019 and is currently developing a Weather and Society Workshop to be held in conjunction with the 2020 Scientific Committee on Antarctic Research (SCAR) meeting in Hobart, Tasmania. It was suggested that a "Special Service Period" be held during austral summer 2020-21, where investment into polar research and services could be assessed in regard to their benefits to operational safety and efficiency.

\subsection{Outcome: YOPP Consolidation Phase}

In July 2019, the PPP moved into its Consolidation Phase. This final phase of the YOPP is crucial to synthesize research efforts from the Preparation and Core Phases, to determine measures of the long-term success of YOPP, and to provide recommendations. A major challenge for YOPP-SH during the Consolidation Phase is to ensure data sharing and coordination of research by the institutions and partners involved with YOPP, as well as to translate the improvement in predictive skill into services and products.

\section{Workshop materials and future workshops}

All of the presentations from the workshops and extended abstracts are available from the websites for the 13th WAMC (2018) (http://amrc.ssec.wisc.edu/meetings/meeting2018.html) and 14th WAMC (2019) (http://amrc.ssec.wisc.edu/ meetings/meeting2019.html). Presentations from both YOPP-SH meetings are available from the YOPP-SH webpage

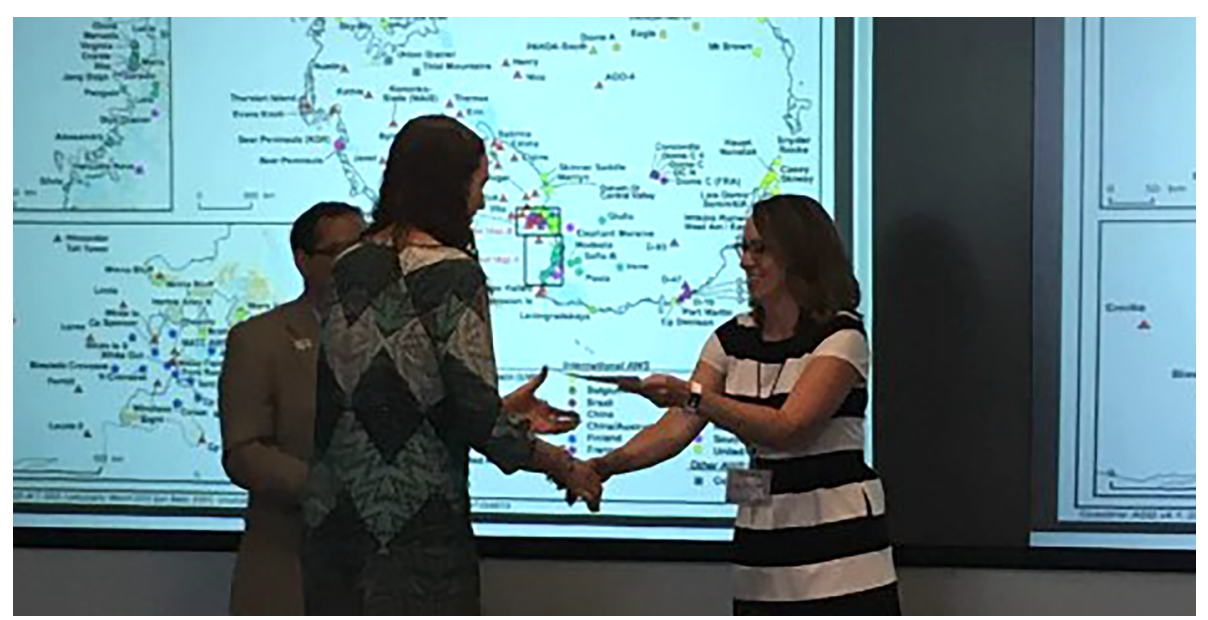

Fig. 5. Claudette ZWEIFEL (right) of the Madison College Grants Office awards Megan JONES (left) of The Ohio State University with the graduate student ICPM/IAMAS travel grant to attend the 13th WAMC. 


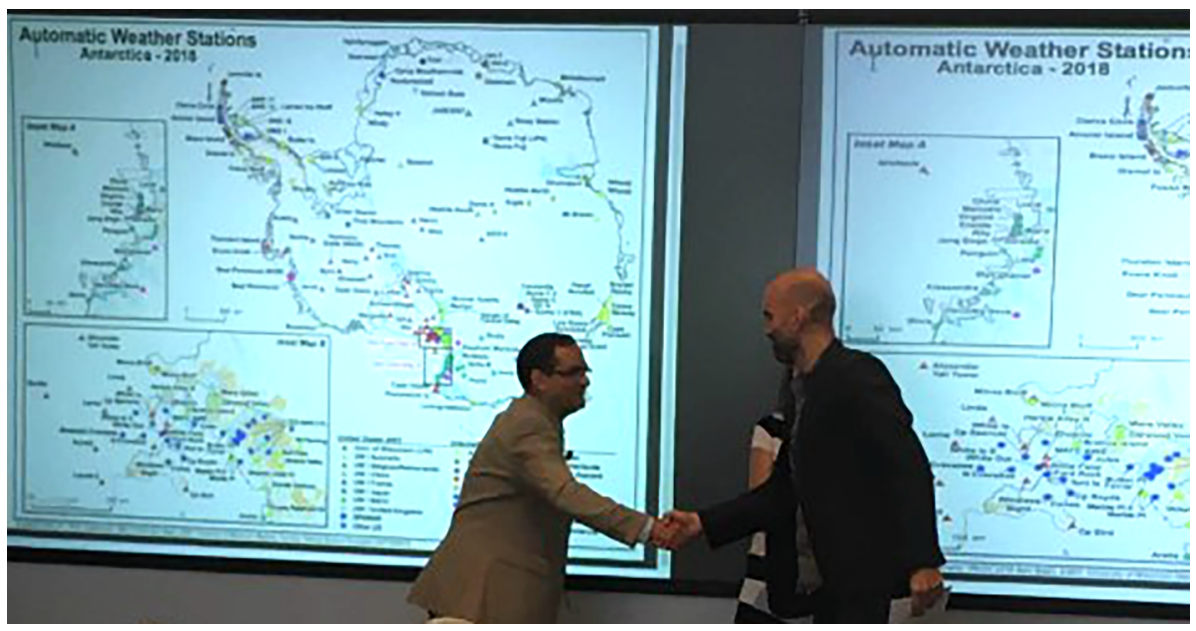

Fig. 6. Matthew LAZZARA (left) of Madison College and University of Wisconsin-Madison awards Deniz BORKUT (right) of the University of Chile with the young scientist ICPM/IAMAS travel grant to attend the 13th WAMC.

(http://polarmet.osu.edu/YOPP-SH/Presentations_201906/) hosted by the Byrd Polar and Climate Research Center. The 15th WAMC will be held in Hobart, Tasmania, Australia in July 2020. Themes for the workshop will continue to be Antarctic observations, numerical modeling, weather forecasting, and meteorological research.

Acknowledgements. The authors wish to thank the International Association of Meteorology and Atmospheric Science (IAMAS)/International Commission on Polar Meteorology (ICPM), SCAR, and the WMO for their travel support of graduate students and young scientists' participation in this workshop along with Madison College's assistance with this (Figs. 5 and 6). Thanks also to Lee WELHOUSE and Dave MIKOLAJCZYK of the University of Wisconsin-Madison for their comments and help. Support from the Office of Polar Programs, National Science Foundation (Grant Nos. PLR-1543305, PLR-1535632, and PLR-1625904), is greatly appreciated.

\section{REFERENCES}

Asuma, J. V., and M. A. Lazzara, 2008: Forecast verification study for McMurdo and Palmer Stations: Preliminary results. In: Antarctic Meteorological Observation, Modeling, and Forecasting Workshop, 3rd, Madison, WI, 9-12 June 2008 (preprints). [Madison, WI], [University of Wisconsin-Madison, Space Science and Engineering Center, Antarctic Meteorological Research Center (AMRC)] http://amrc.ssec.wisc.edu/meetings/meeting2008/abstracts/asuma.pdf.

Carrasco, J., and P. Uribe, 2019: Meeting and open session of the World Meteorological Organization's The Polar Prediction Project's (PPP) Societal and Economic Research and Applications (SERA) task team: Travelling to Antarctica: A conversation on Antarctic environmental forecasting services to improve the safety of operational, touristic and research activities. Polar Journal, 9(1), 264-267, https://doi.org/10.1080/2154896X.2019.1622897.

Colwell, S. R., A. M. Cayette, M. A. Lazzara, J. G. Powers, D. H. Bromwich, J. J. Cassano, and S. Carpentier, 2016: The 10th Antarctic meteorological observation, modeling, and forecasting workshop. Adv. Atmos. Sci., 33(5), 656-658, https://doi.org/10.1007/ s00376-016-6012-3.

Hines, K. M., D. H. Bromwich, S. H. Wang, I. Silber, J. Verlinde, and D. Lubin, 2019: Microphysics of summer clouds in central west Antarctica simulated by Polar WRF and AMPS. Atmospheric Chemistry and Physics Discussions, https://doi.org/10.5194/acp2018-125.

Hong, S. Y., J. Dudhia, and S. H. Chen, 2004: A revised approach to ice microphysical processes for the bulk parameterization of clouds and precipitation. Mon. Wea. Rev., 132, 103-120, https://doi.org/10.1175/1520-0493(2004)132<0103:ARATIM>2.0.CO;2.

Kameda, T., S. Takahashi, H. Enomoto, and H. Motoyama, 2008: Automatic weather station research by Japanese Antarctic research expedition in east droning Maud land, east Antarctica. Tenki, 55(11), 901-906.

Lazzara, M. A., J. G. Powers, C. A. Costanza, D. H. Bromwich, S. Carpentier, and S. R. Colwell, 2018: The 12th workshop on Antarctic meteorology and climate. Adv. Atmos. Sci., 35(7), 753-756, https://doi.org/10.1007/s00376-018-8061-2.

Seefeldt, M. W., T. Yoksas, and M. A. Lazzara, 2009: The distribution, retrieval, and visualization of real-time Antarctic numerical weather prediction, satellite, and observational data. Proc. 10th Conf. on Polar Meteorology and Oceanography, Boston, MA, American Meteorological Society.

Skamarock, W. C., J. B. Klemp, J. Dudhia, D. O. Gill, Z. Q. Liu, J. Berner, W. Wang, J. G. Powers, M. G. Douda, D. M. Barker, and X. Y. Huang, 2019: A description of the advanced research WRF model version 4. No. NCAR/TN-556+STR, $162 \mathrm{pp,}$ https://doi.org/10.5065/1dfh-6p97. 